\title{
LETTERS
}

\section{What to do about the Canadian residency matching process?}

I read with interest the article published in CMAJ on Nov. 27, 2017, ${ }^{1}$ titled "What to do about the Canadian Resident Matching Service." I would like to start by stating I agree with the importance of the issues raised in this article, and the need for discussion and collaboration on potential improvements in the resident matching system and its supporting structures.

It is true that the current system has its challenges, which can lead to uncertainty, anxiety, an increasing work effort on the part of everyone involved and, yes, a rising number of unmatched Canadian medical graduates in recent years.

The application, selection and matching process for more than 3000 medical school graduates and postgraduate positions is a high-stake one. At the end of it all, an average $97 \%$ of Canadian medical school graduates begin postgraduate training in the year they graduate from medical school, while more than 99\% begin postgraduate training within two years after graduation. But there are also other outcomes that matter, and to address them we need to be looking at the entirety of the system. In this regard, we at the Canadian Residency Matching Service (CaRMS) agree with our colleagues throughout the medical education community: together, we can and must do better for those for whom the system has not worked.

When we talk about the residency matching system in Canada, it is important to note that CaRMS is one of many entities that work together in this area. As the authors themselves outline very clearly, the matters raised transcend the boundaries of CaRMS and encompass provincial governments, learner organizations and medical faculties, along with many other inputs and decision-makers. At CaRMS, we are responsible for managing the residency match process, and we do so according to the policies dictated by provinces and faculties. The outcomes of the processes we administer are determined by these policies and the decisions of match participants. For this reason, Drs. Wilson and Bordman's interesting and thought-provoking article may have been more appropriately titled "What to do about the Canadian residency matching process?".
As Chair of the CaRMS Board of Directors, I can say that CaRMS is eager and willing to work with all our partners across medical education and to bring our knowledge and expertise to bear on this important issue. We look forward to being at the table when our community discusses ways we can work collectively toward better outcomes at a system level - for applicants, for faculties of medicine and, most importantly, for the health needs of Canadians.

\section{Janice Willett MD}

Associate Dean, Faculty Affairs and Continuing Education and Professional Development, and Associate Professor, Northern Ontario School of Medicine, Thunder Bay, Ont.; Chair, CaRMS Board of Directors

n Cite as: CMAJ 2018 January 29;190:E117. doi: $10.1503 / \mathrm{cmaj} .68733$

\section{Reference}

1. Wilson CR, Bordman ZN. What to do about the Canadian Resident Matching Service. CMAJ 2017; 189: E1436-47.

Competing interests: Janice Willett is the Chair of the Canadian Residency Matching Service Board of Directors. 